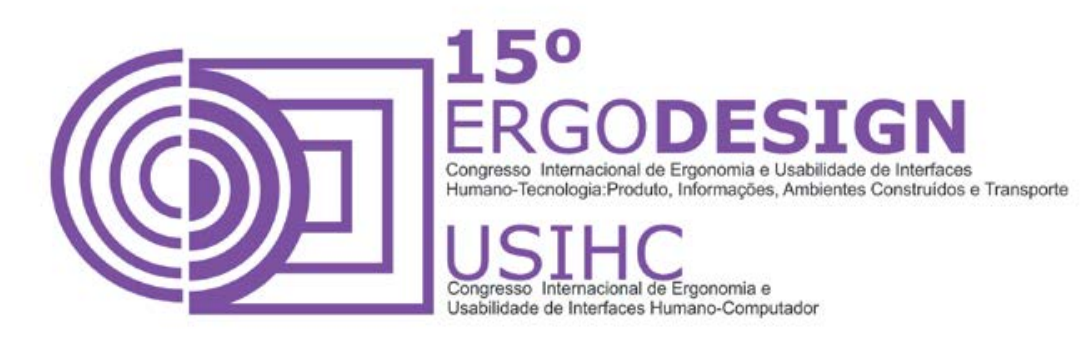

\title{
PROJETO DE INTERFACE GRÁFICA TOUCH SCREEN PARA O CARDIOVERSOR LIFESHOCK-PRO
}

\section{A PROJECT OF TOUCH SCREEN GRAPHIC INTERFACE FOR CARDIOVERTER LIFESCHOCK-PRO}

\author{
SENNA, Carlos Eduardo (1); \\ FRANZ, Ismael Hippen (2); \\ DORSA, Mateus Régis (3); \\ (1) Universidade Federal do Rio Grande do Sul, Doutorando em Design \\ e-mail: carlossenna@gmail.com \\ (2) Instituto Nacional de Pós-Graduação INPG/Sustentare, Pós-Graduado em Design, \\ Desenvolvimento de Produtos e Gestão \\ e-mail: franz.ismael@gmail.com \\ (3) Instituto Federal de Santa Catarina, Graduado em Design de Produto \\ e-mail: mdorsa@gmail.com
}

\begin{abstract}
RESUMO
O presente artigo descreve o desenvolvimento de uma interface gráfica, com comandos touch screen, para um equipamento eletromédico, denominado Lifeshock-Pro. O projeto, realizado em parceria com as empresas TOTH Tecnologia e LIFEMED, contou com a identificação dos dispositivos existentes no mercado, levantamento das funções envolvidas e proposição de telas, com adequação das informações prioritárias. Um dos grandes desafios no desenvolvimento de produtos médico-hospitalares diz respeito a prevenção de erros. Nesse sentido, para tornar a interface mais simples e intuitiva, a proposta seguiu os preceitos de usabilidade, as diretrizes da American Heart Association (2010) e as recomendações normativas existentes na série IEC 60601 e na ISO 9241(2011).
\end{abstract}

Palavras-chave: Interface Gráfica, Cardioversor, Usabilidade

\section{ABSTRACT}

The present article describes the development of a graphic interface with touch screen system for an electromedical equipment named Lifeshock-Pro. The project, which was conducted in partnership with 


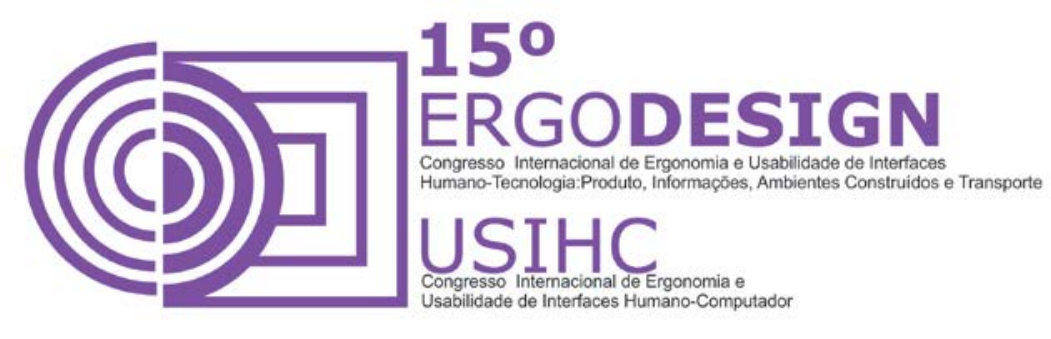

TOTH Technology and LIFEMED, identified the devices available in the market, listed their functions and the display of the screens, and their appropriateness regarding the prioritary information. One of the most challenging phases in the development of medical and hospital products is related to the prevention of mistakes. In this sense, in order to make the interface simple and intuitive, the proposal followed the usability concepts, the guidelines from the American Heart Association (2010) and the normative recommendations in the series IEC 60601 and in the ISO 9241 (2011).

Keywords: Graphic Interface, Cardioverter, usability

\section{INTRODUÇÃO}

O cardioversor Lifeshock-Pro é um produto composto por duas funções principais: a de desfibrilador bifásico e a de monitor. Trata-se de um equipamento eletromédico, destinado à desfibrilação e à verificação de sinais vitais em pacientes adultos, pediátricos e neonatais.

Utilizado principalmente durante uma parada cardiorrespiratória (PCR), o cardioversor tem como objetivo principal restabelecer ou reorganizar o ritmo cardíaco de uma pessoa, revertendo um possível quadro emergencial. Na prática, o produto efetua a leitura automática do ritmo cardíaco por meio das pás, que são fixadas no tórax do paciente. No modo desfibrilador externo semiautomático (DEA), além de checar os sinais vitais do paciente, o produto é capaz de aplicar uma corrente elétrica, fazendo com que o coração retome o ciclo cardíaco normal. Em suma, é um produto altamente recomendado, tanto em unidades de emergência quando em unidades de terapia intensiva (UTIS).

Mesmo sendo classificado como dispositivo eletromédico, em diversos países, a aquisição e utilização do DEA é livre e incentivada, principalmente por possibilitar a aplicação imediata da ressuscitação cardiopulmonar (RCP) enquanto o serviço de emergência não chega no local. De acordo com Gonzalez et al. (2013), em uma vítima de parada cardiorrespiratória, o ideal é que se realize o procedimento dentro dos primeiros 3 a 5 minutos. Para o autor, "a cada minuto transcorrido do início do evento arrítmico súbito sem desfibrilação, as chances de sobrevivência diminuem em 7 a 10\%" (GONZALEZ et al., 2013, p.04).

Apesar de existir o incentivo para o uso do equipamento, um problema aparente, alertado pela American Heart Association ${ }^{1}$ (2010), é que a maioria das vítimas de PCR extra-hospitalar não recebe nenhuma manobra imediata de RCP. Tal procedimento poderia ser feito pelas próprias

\footnotetext{
${ }^{1}$ American Heart Association: As diretrizes da AHA (2010) se baseiam em uma ampla revisão literária para Ressuscitação Cardiopulmonar (RCP) e Atendimento Cardiovascular de Emergência (ACE). O documento contêm recomendações que são utilizadas em Consenso Internacional.
} 


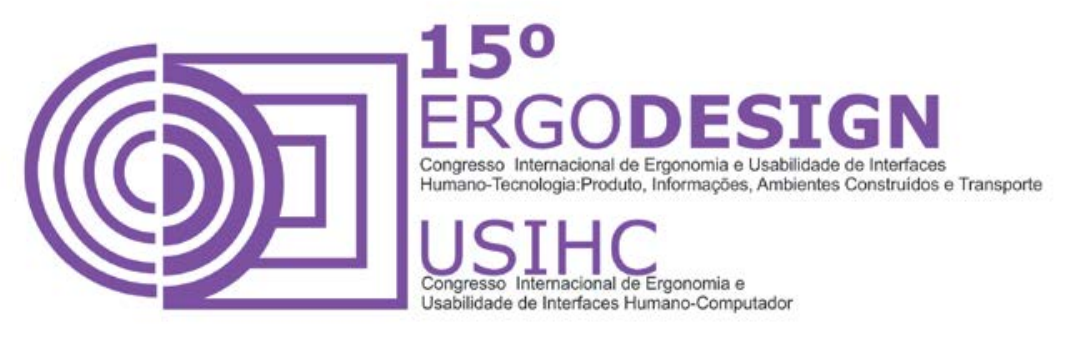

pessoas presentes no local, se as mesmas tivessem ciência das ações necessárias para realizar a atividade ${ }^{2}$.

Pensando nisso, foi desenvolvida uma interface gráfica, com comandos touch screen, para o equipamento em questão, constituído de corpo único com tela de 8,4 polegadas e resolução de 800 X 600 pixels. A sequência de procedimentos de RCP foi estudada para a composição das telas, fornecendo instruções simples e avisos atuais sobre o estado de saúde do paciente. Além disso, foram estabelecidos comandos de voz, utilizados para reforçar as mensagens no visor.

A tecnologia de toque direto na tela, para acionamento das funções, precisou passar por uma análise crítica da tarefa, para garantir a usabilidade correta da interface. Vale lembrar que a proposta também seguiu as recomendações da série IEC 60601 e da norma ISO 9241(2011), que fornece orientações para desenvolvimento de produtos com foco na usabilidade.

\section{PROBLEMA DE PROJETO}

O Lifeshock-Pro foi desenvolvido para ser o primeiro cardioversor do mundo com navegação predominantemente touch screen. Por conta disso, as exigências de projeto voltaram-se para 0 entendimento dos modos de operação, exigidos na manipulação do objeto. Se por um lado não há dúvida que as interfaces touch screen são peças importantes na forma como as pessoas irão interagir no futuro (BRANDÃO, 2012). Por outro lado, é preciso lembrar que equipamentos médico-hospitalares requerem confiabilidade total no seu uso, pois são produtos utilizados em situações críticas.

Sendo assim, a questão básica que norteia este estudo pode ser expressa da seguinte forma: De que maneira a interface gráfica, com tecnologia touch screen, pode auxiliar um socorrista em uma ressuscitação cardiopulmonar? Algumas sugestões e apontamentos serão tratadas no decorrer do texto.

\section{MÉTODOS E TÉCNICAS}

\subsection{Briefing}

Inicialmente, a proposta contou com a elaboração de um briefing, redigido por profissionais da área médica, engenheiros e designers. Para fins didáticos, foram separadas as principais características da interface gráfica:

- A parte de configuração do produto deveria ser acessada por botões touch screen;

- A tela deveria ser de fácil visualização, proporcional à distância de leitura do observador;

\footnotetext{
${ }^{2}$ A desfibrilação precoce é uma manobra utilizada durante uma parada cardiorrespiratória. Pode ser feita por um equipamento manual (somente manuseado pelo médico) ou com o DEA, que pode ser utilizado por qualquer pessoa assim que possível (GONZALEZ et al., 2013, p.08).
} 


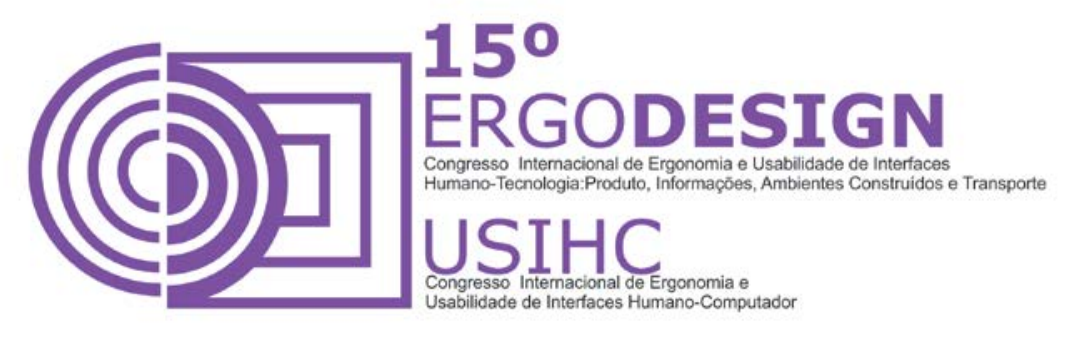

- As telas deveriam mostrar os parâmetros clínicos do paciente (por traçados elétricos);

- A interface gráfica deveria ser coerente com a parte externa do produto (conhecida como carenagem ou gabinete);

- As telas deveriam respeitar a densidade de 119,25 DPI (pontos por polegada);

- As telas deveriam ser construídas para o modo VGA (800 X 600 pixels);

- Para o código tipográfico, poderiam ser utilizados de dois a três tamanhos pré-definidos de fontes, de modo a evitar sobrecarrega visual;

- No modo DEA, a mensagem deveria ser intuitiva, com leitura imediata.

Devido às exigências para aprovação do produto nos órgãos competentes como INMETRO e ANVISA, além das especificações de design, existiram restrições de ordem técnica, que foram incorporadas imediatamente ao projeto. Por exemplo, os desenhos de alguns ícones seguiram as recomendações previstas na IEC 60878 (2003), que trata dos símbolos padronizados em equipamentos eletroeletrônicos. Outras exigências também foram vistas na série IEC $60601 \mathrm{e}$ na norma ISO 9241(2011), que orienta desenvolvimento de produtos com foco na usabilidade.

\subsection{Análise dos dispositivos existentes no mercado}

Após a definição do briefing e, com o intuito de dar sequência às informações sobre os cardioversores, aplicou-se a técnica de análise de produtos similares (figura 1). A análise de produtos similares aparece na literatura do design sob terminologias diferentes. Os nomes mais comuns são: análise da concorrência, análise competitiva (competitive analysis) e análise paramétrica (PADOVANI; SPINILLO; GOMES, 2009). Na prática, os produtos "competidores" foram apresentados e suas vantagens, discutidas. Como resultado da aplicação da técnica, foi obtida uma listagem, que contempla características desejáveis e aspectos desfavoráveis, que foram explorados ou simplesmente evitados na nova proposta. 


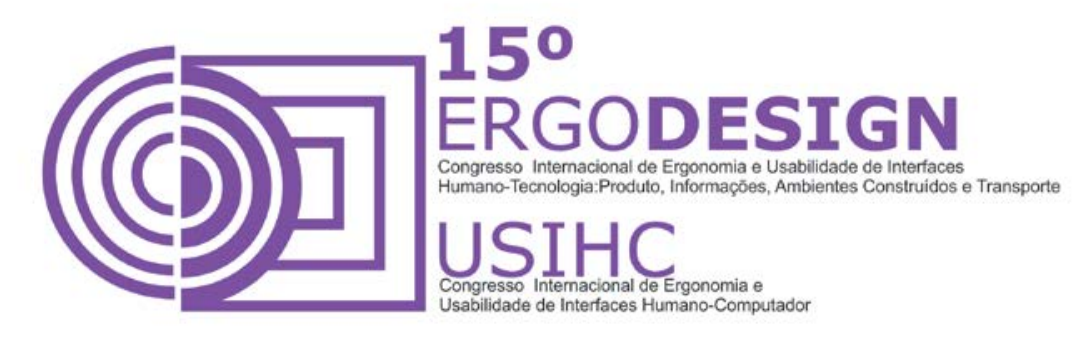

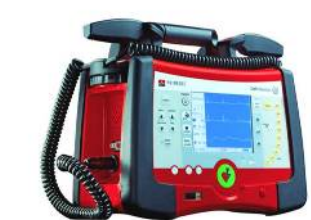

Primedic (Defi-Monitor XD)

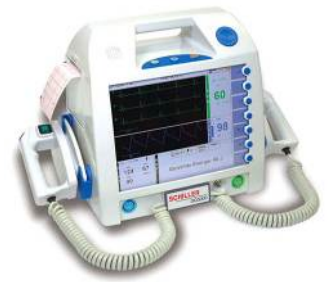

Schiller Medical (Defigard 5000)

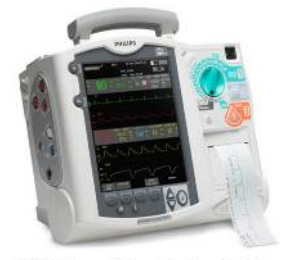

Philips Heartstart Mrx (M3535A/M3536A)

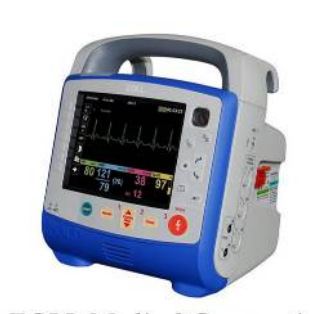

ZOLL Medical Corporation (Propaq MD)

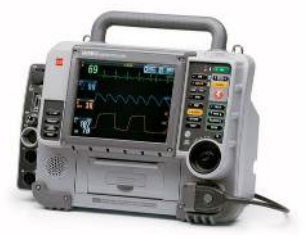

Physio-Control (LifePak 15)

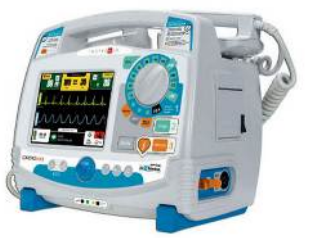

Instramed (Cardiomax)

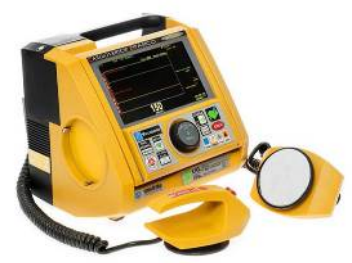

Cmos Drake (Cardioversor Vivo)

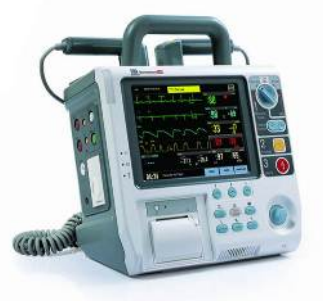

Mindray (Beneheart D6)

Figura 1 - Principais cardioversores disponíveis no mercado.

No que se refere à interface gráfica, foi visto que os produtos apresentam muitas informações textuais, botões físicos (localizados, principalmente, à direita do visor), seletores e linhas de comando. Também foi constatado que o uso de cores na tela é feito de modo contido, ficando restrito a pequenas regiões da superfície. Existe o predomínio por telas com fundo preto e as informações são mostradas em cores contrastes com o fundo. No modo DEA, grande parte dos cardioversores apresentou somente ordens escritas, o que não é considerado ideal para um equipamento que precisa ser intuitivo. Ainda no modo DEA, vale destacar que alguns produtos apresentaram imagens associadas às instruções textuais, que são repassadas ao socorrista por ordens de comando. Apesar de a ideia ser favorável (passível de ser aplicada no LifeshockPro), as imagem tinham baixa resolução, o que prejudicava a leitura e o entendimento dos modos de operação.

Com a análise, foi possível perceber que os novos carvioversores estão deixando de ter apenas informações textuais. Esta realidade é compartilhada por Silva (2008), que cita que as interfaces dos equipamentos médico-hospitalares mais recentes estão trazendo gráficos, telas de navegação, comandos por toques em tela (touch screen), comandos por voz, mensagens de alerta, informações de apoio à decisão, entre outros fatores.

\subsection{Levantamento das funções envolvidas}

De posse dessas informações (mercadológicas e de ordem técnica), o próximo passo consistiu em entender os modos de operação desempenhados pelo objeto. No modo de monitorização, 


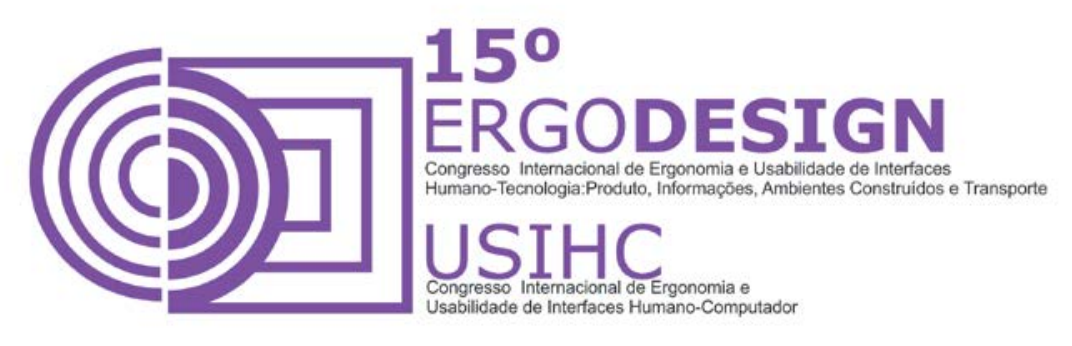

ficou entendido que o objeto deveria ser capaz de verificar parâmetros como: o traçado de eletrocardiograma (ECG), a frequência cardíaca (FC), a oximetria de pulso (SpO2) e a pressão arterial não invasiva (PNI). As medidas desses parâmetros deveriam ser mostradas no visor. Além disso, existem alarmes disponíveis que indicam alterações na condição do paciente, que foram estudados em paralelo com as funções de monitorização.

Já, no modo desfibrilador externo semiautomático (DEA), foi visto que produto deveria seguir alguns algoritmos de tratamento-padrão para parada cardíaca, que auxiliam o socorrista a reverter possíveis arritmias, potencialmente fatais. No atendimento de uma Ressuscitação Cardiopulmonar são exigidos procedimentos de reconhecimento internacional. Sendo assim, 0 estudo buscou suporte nas diretrizes da American Heart Association, considerada referência para o assunto no meio acadêmico.

Durante o estudo, foi percebido que, no ano de 2010, a American Heart Association realizou uma alteração significativa na sequência de procedimentos de RCP. O atendimento que, até então, preconizava a sequência A-B-C (via aérea, respiração, compressões torácicas) passou a ser redigido na forma C-A-B (compressões torácicas, via aérea, respiração) para adultos, crianças e bebês (excluindo-se recém-nascidos). Estas alterações direcionaram a composição de telas do cardioversor, que foram planejadas de forma a orientar o socorrista em uma abordagem sistemática. O resultado deste estudo gerou o fluxograma a seguir, com todos os passos necessários para operação do sistema. 


\section{(C)]}
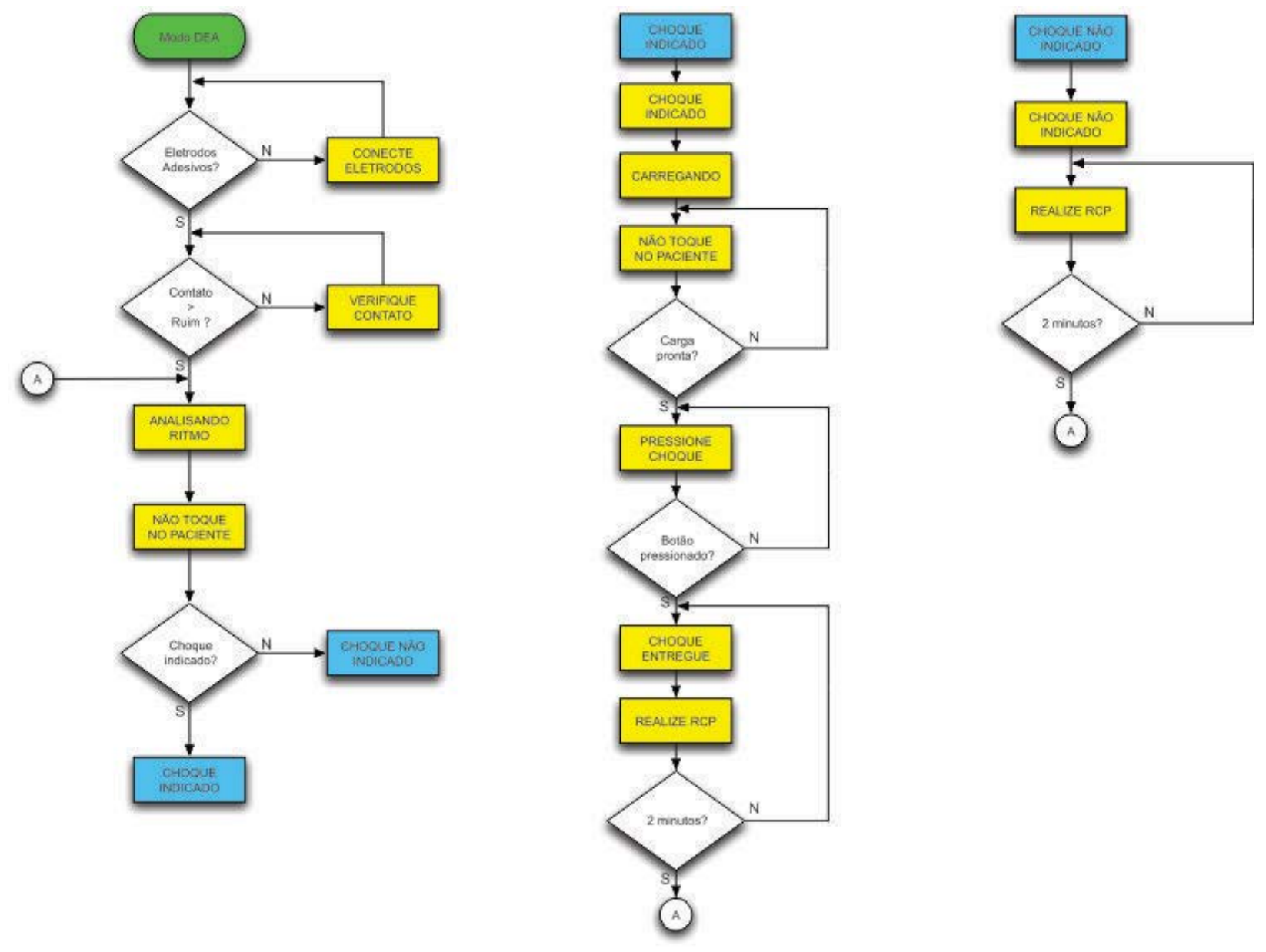

Figura 2 - Fluxograma com os procedimentos de RCP sugeridos para o modo DEA.

É notório que no exercício da prática médica há grande quantidade de conhecimento técnico, que os profissionais devem absorver e usar em sua rotina. Concorrem, com a atenção do médico, os dispositivos com os quais ele interage, que são cada vez mais sofisticados. Para Urtiga (2008, p.35) "A soma desses fatores pode implicar numa sobrecarga cognitiva para esses usuários que, ao mesmo tempo, dispensam cuidados ao paciente e lidam com complexas interfaces que alguns desses sistemas apresentam". Como o principal objetivo do projeto é produzir um sistema funcional e seguro, centrado no usuário e que prime pela usabilidade, é imprescindível considerar a Interação Humano Computador (IHC), ergonomia visual/cognitiva e seus preceitos de usabilidade.

A análise heurística dos princípios ergonômicos e de usabilidade é um assunto abordado por diferentes autores, dentre eles destacam-se Nielsen (1993) e Fleming (1998). Embora cada autor possua suas particularidades, ambos apresentam recomendações de destaque. Neste 


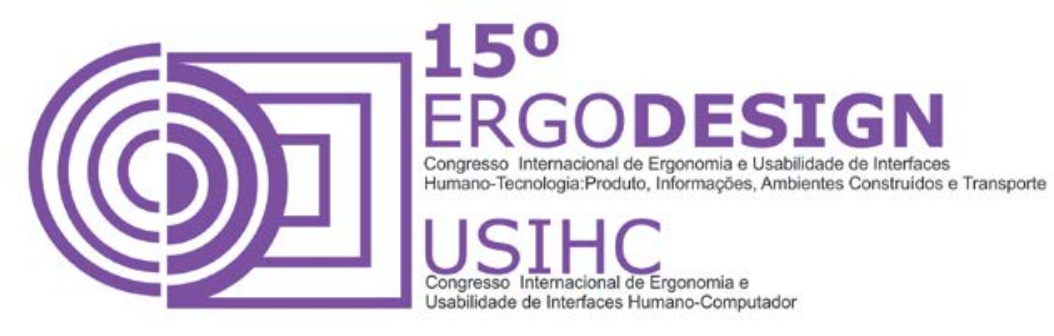

projeto em especial, utilizou-se, principalmente, os princípios da facilidade de aprendizado; consistência e padrão; economia de ações e tempo de utilização, apresentação de mensagens visuais claras e no momento adequado; rótulos compreensíveis; prevenção de erros; e estética e design minimalista. Contudo, um dos principais conceitos abordados por Nielsen (1993), foi aplicado em todas as telas desenvolvidas, o minimalismo. Por se tratar de um equipamento utilizado em situações de risco, é imprescindível a rápida percepção e o entendimento do usuário, e isso passa pela redução das informações presentes na tela.

Sob a ótica das metas de usabilidade, Preece (2005) aborda, por um outro viés, os mesmos pontos acima descritos. Para o autor, a usabilidade é dividida em: ser eficaz no uso (eficácia); ser eficiente no uso (eficiência); ser segura no uso (segurança) ser de boa utilidade (utilidade); ser fácil de aprender (learnability) e ser fácil de lembrar como se usa (memorability). Estes preceitos corroboram com as normas utilizadas para desenvolvimento do Lifeshock-Pro, a NBR 9241-11 (2011) que traz orientações sobre usabilidade e equivalente à ISO 9241-11. Para tratar especialmente da usabilidade em sistemas médicos, a International Eletrotechnical Commission (IEC) emitiu a norma 60601-1-6, que apresenta requisitos para projeto, análise, verificação e validação de usabilidade para equipamentos médico-hospitalares.

No plano de estruturas, a fim de organizar e priorizar as informações a serem apresentadas nas telas de navegação, fez-se necessário um estudo da arquitetura da informação indicadas para compor o produto. Nesta etapa, por meio de um diagrama (também chamado de árvore de funções), foi definida a forma como os usuários navegariam no sistema. O diagrama foi composto para organização hierárquica das funções/menus. Com ele, foi possível ordenar toda a sequência de navegação, para posterior representação visual da interface, tratando das páginas e dos conteúdos embarcados, assim como a entrada de todas as transações.

Devido a sua complexidade, a árvore de funções, com todos os desdobramentos e páginas, foi feita com auxílio do software Free Mind. Depois dessa etapa, ficou mais claro para a equipe de projeto os modos distintos de operação do produto, com suas subfunções e telas. Sendo assim, a informação foi organizada no modo DEA, no modo Desfibrilador, no modo Marcapasso e no modo Monitoramento. Também foi feita a parte de configuração do aparelho, que descreve os ajustes necessários.

Uma vez entendido os modos de operação, o próximo passo foi criar o recurso de wireframe no plano de esqueleto (figura 3), com a localização dos elementos da interface e determinação da posição de cada conteúdo. Com esta organização visual foi possível manter a mesma diagramação para as diferentes telas do cardioversor. Na concepção de Wodtke (2009) 0 wireframe é a visualização - de forma simples e contendo apenas os detalhes indispensáveis da disposição dos elementos que compõem o layout. É o primeiro documento, que começa a dar forma à interface gráfica com representação dos elementos que define a hierarquia entre eles, seus agrupamentos e importâncias relativas. 

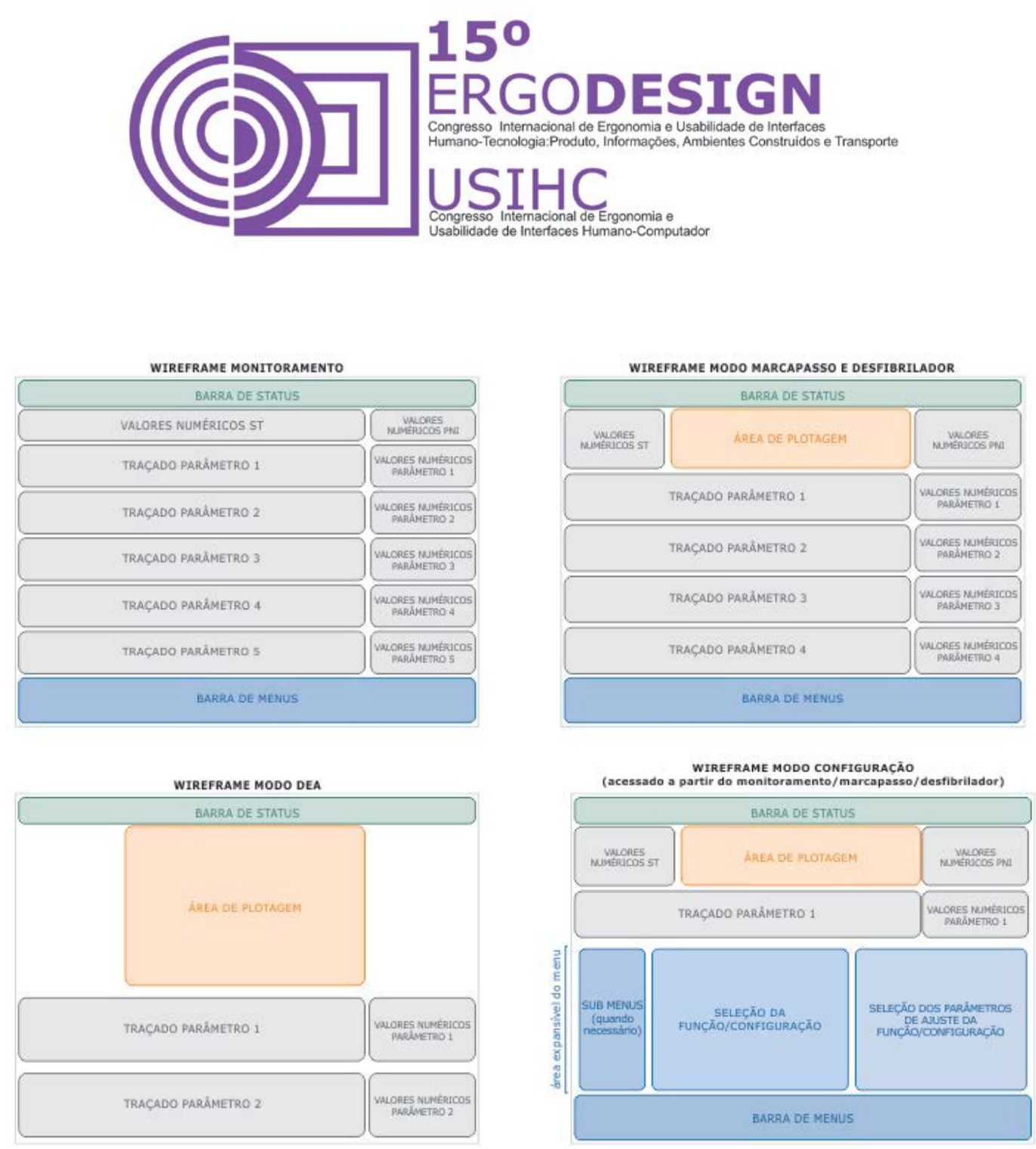

Figura 3 - Wireframe das telas (desenvolvido a partir do entendimento dos modos de operação).

Segundo Preece (2005, p.293) "uma boa organização auxilia os usuários a compreender e interpretar a interação dentro de seu próprio contexto". Sendo assim, foi atendido um dos princípios básicos da usabilidade, criando o padrão e a unidade que facilita o aprendizado e memorização das posições, além de gerar maior eficiência e eficácia no manuseio. No topo de todas as telas, encontra-se a barra de status, que exibe informações de conectividade, bateria, data/hora e identificação do paciente. Por outro lado, na base, localiza-se a barra de menus, com os ícones das principais funções de cada modo. Ambas as barras ficam sempre visíveis, exceto no modo DEA, que ela é suprimida.

A área de plotagem no centro das telas dos modos marcapasso, desfibrilador e DEA, são espaços de destaque com as informações principais que o usuário precisa para cada modo de operação. A área com maior destaque é destinada ao DEA, pois é onde será realizada toda a comunicação interativa, com as instruções para o usuário operar no modo semiautomático.

A configuração do equipamento pode ser acessada selecionando-se um dos ícones na barra de menus. Neste momento a área de menu é expandida para permitir a configuração do produto. Todavia ficam visíveis até dois traçados, o que garante que mesmo ajustando o equipamento o 


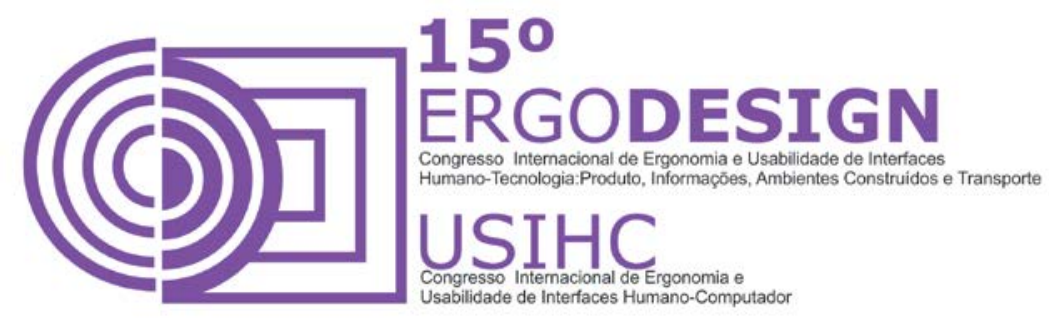

usuário possa permanecer com os sinais vitais do paciente no seu campo visual. Essa redução de traçados visíveis ocorre também no modo DEA, deixando a tela apenas com as informações fundamentais, o que facilita a compreensão pelo usuário. A área expansível é composta por até 3 sub-áreas: submenus, visível somente quando necessário; lista das funções a serem configuráveis; e as opções dos parâmetros ajustáveis da função selecionada.

\section{Proposição das telas}

Definido o wireframe das telas, o próximo passo foi dado com a concepção dos elementos visuais. Dispostos sob um fundo preto, as informações de traçado e os valores numéricos foram plotados na tela, de acordo com as especificações mostradas nos tópicos anteriores. A partir do monitoramento, marcapasso ou desfibrilador, é possível acessar os menus de configuração do equipamento. A tela apresenta informações do status atual da função selecionada e possui sistema de feedback por cores e formas diferenciadas. Visualmente, o modo marcapasso e o modo desfibrilador diferenciam-se do modo monitoramento, devido ao destaque dado para a área de plotagem. Com fundo branco e fontes maiores, a proposta assegura a identificação das informações principais para cada operação.
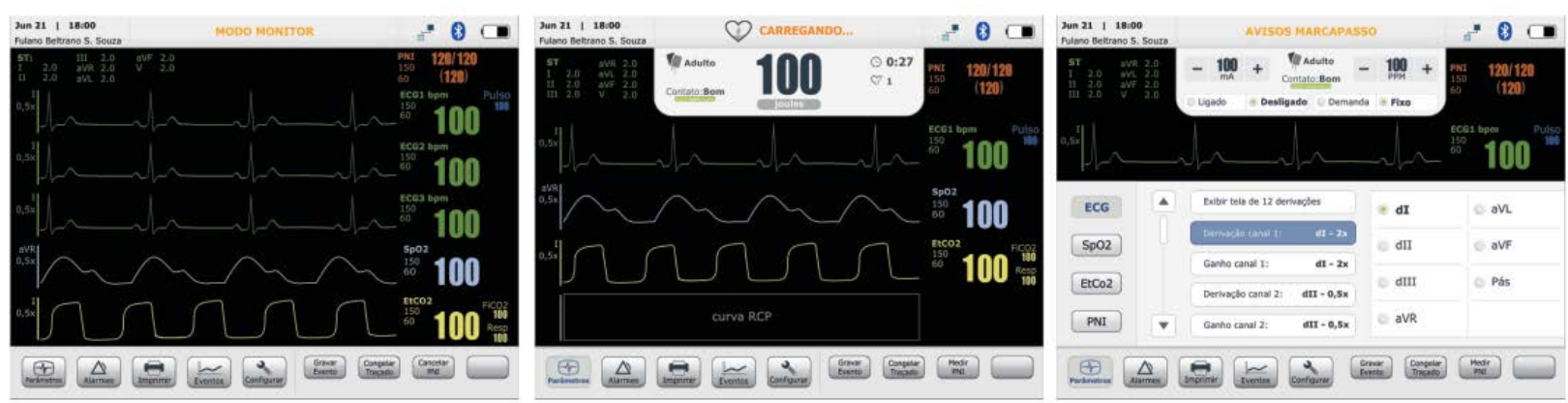

Figura 4 - Telas concebidas para o modo monitoramento, modo desfibrilador e modo marcapasso (acessando o menu de configuração)

Para o modo DEA, as telas apresentaram em conjunto imagens e instruções textuais, indicando as ações que o socorrista deve tomar. Diferente das propostas já existentes no mercado, a solução encontrada cria ilusão de movimento por alternância de telas, com duas imagens que se sobrepõem a cada segundo (ver figura 5). A ideia induz a percepção humana à identificar a ação, que deve ser realizada imediatamente.

A composição das telas para sequência de RCP segue os preceitos ergonômicos e fornece instruções simples, com avisos atuais sobre o estado de saúde do paciente. Além das mensagens visuais e textuais, há o reforço por comandos de voz. São ações sincronizadas que emitem sempre a mesma informação ao usuário por estímulos diferentes, garantindo que o mesmo possa manter atenção durante a tarefa. Para Cybis (2007), a atenção envolve o foco ou a concentração dos processos cognitivos sobre um objeto ou pensamento a partir das percepções de seus sentidos auditivos e visuais. Embora a visão seja o principal sentido do ser 


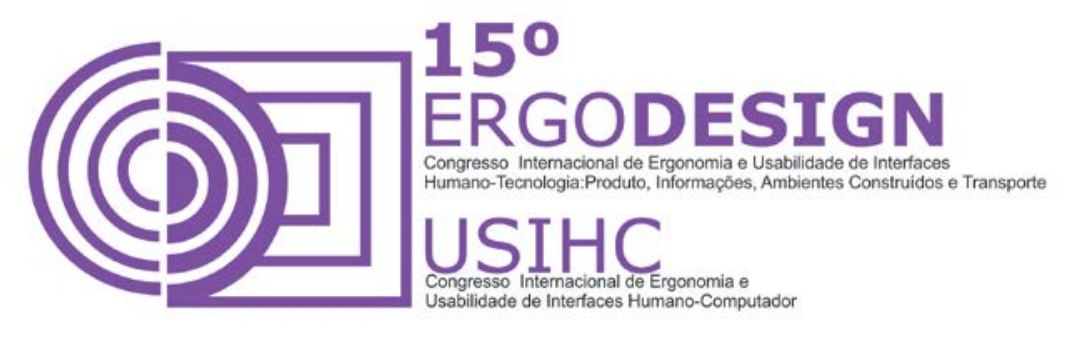

humano, quando a mesma está sobrecarregada, ou em estado crítico (como no caso de atendimentos de emergência) pode-se utilizar o canal auditivo, seja para reforçar ou para enviar novas informações.
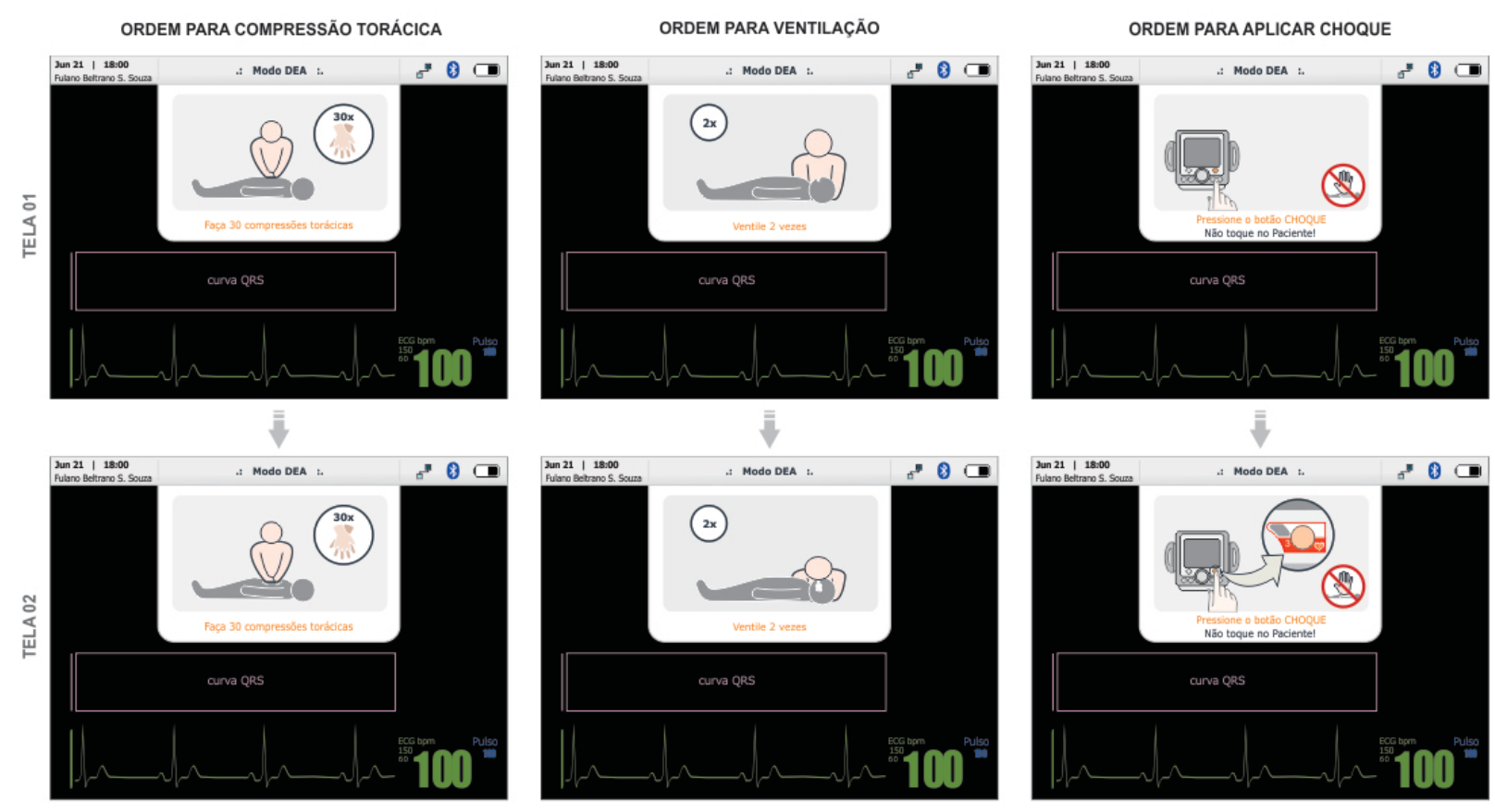

Figura 5 - Exemplo de três ações que simulam movimento por alternância de telas

\section{CONCLUSÃO}

Este artigo resume os principais pontos trabalhados no processo de desenvolvimento de uma interface gráfica. A proposta foi desenhada para atender às exigências de um equipamento eletromédico, destinado à monitorização e à ressuscitação de um paciente.

Utilizando os preceitos de usabilidade e as diretrizes da American Heart Association (2010), as telas foram cuidadosamente organizadas, de modo a facilitar o uso do equipamento. Além disso, as informações apresentadas no visor, foram direcionadas para a tarefa em andamento, propiciando ao usuário (no caso, o socorrista) facilidade na navegação e rapidez em encontrar a informação.

A solução concebida para o modo de operação DEA, por exemplo, cria ilusão de movimento por alternância de telas. A sequência de procedimentos de RCP é passada ao usuário por intercâmbio gráfico, simulando o passo a passo a ser realizado de forma simplificada. Aliada à parte gráfica, foram trabalhados informações textuais e comandos de voz, utilizados para reforçar a mensagem. 


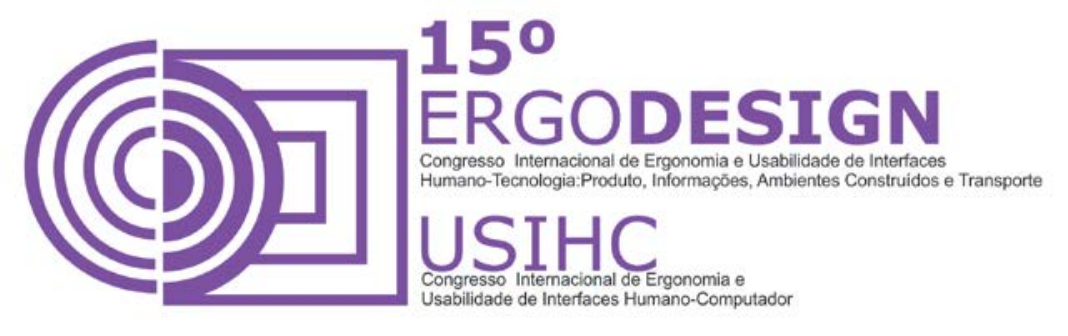

Ao avaliar o estudo realizado, notou-se um campo vasto sobre a tecnologia touch screen, ainda recente nos equipamentos eletromédicos. Esta constatação indica que há muitas vertentes para pesquisas, testes e aplicações em produtos similares. No caso do Lifeshock-Pro, após validar as telas, a resposta superou as expectativas da área de design (ver figura 6). Hoje, o produto é utilizado no Hospital São Lucas, da Pontifícia Universidade Católica do Rio Grande do Sul, e no Instituto de Cardiologia de Porto Alegre.
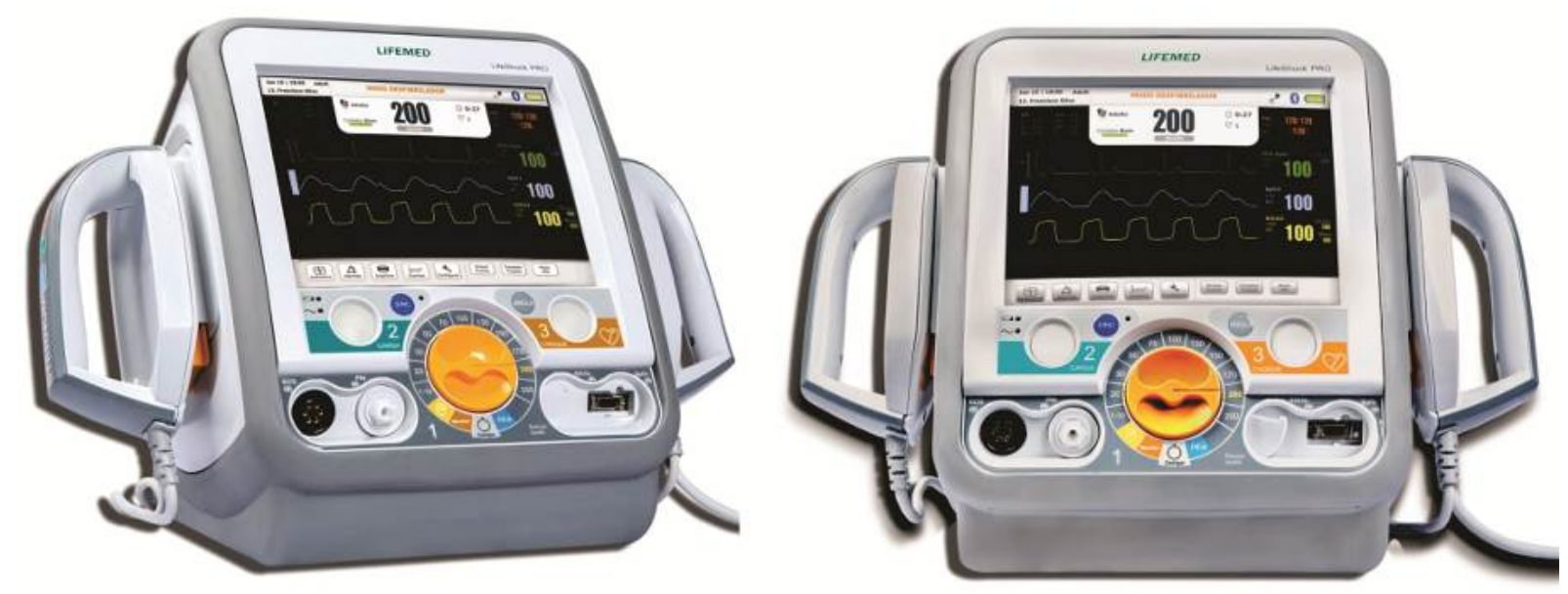

Figura 6 - Interface gráfica aplicada no produto

\section{REFERÊNCIAS BIBLIOGRÁFICAS}

AMERICAN HEART ASSOCIATION. Guidelines for Cardiopulmonary Resuscitation and Emergency Cardiovascular Care Science. Dallas: Published by AHA, 2010. ISSN: 1524-4539. Disponível em: <http://circ.ahajournals.org/content/122/18_suppl_3/S639.full>. Acesso em: 02 jun. 2010.

ASSOCIAÇÃO BRASILEIRA DE NORMAS TÉCNICAS. NBR 9241-11: Requisitos ergonômicos para o trabalho com dispositivos de interação visual. Parte 11: Orientações sobre usabilidade. Rio de Janeiro: ABNT, 2011.

BRANDÃO, Eduardo Rangel. Interfaces touch-screen. Aula ministrada no curso de Pós-Graduação em Ergodesign de Interfaces: Usabilidade e Arquitetura de Informação. Rio de Janeiro: Pontifícia Universidade Católica do Rio de Janeiro, 2012. 59 slides. Disponível em:

<http://www.eduardobrandao.com/aulas/design-telas/interfaces-touch-screen/>. Acesso em: 3 out. 2012.

CYBIS, W; Betiol, A.; FAUST, R. Ergonomia e Usabilidade: Conhecimentos, Métodos e Aplicações, Novatec, 2007.

FLEMING, Jennifer. Web Navigation: Designing the User Experience. Sebastopol, O'Reilly \& Associates, 1998.

GONZALEZ, MM et al. I Diretriz de Ressuscitação Cardiopulmonar e Cuidados Cardiovasculares de 


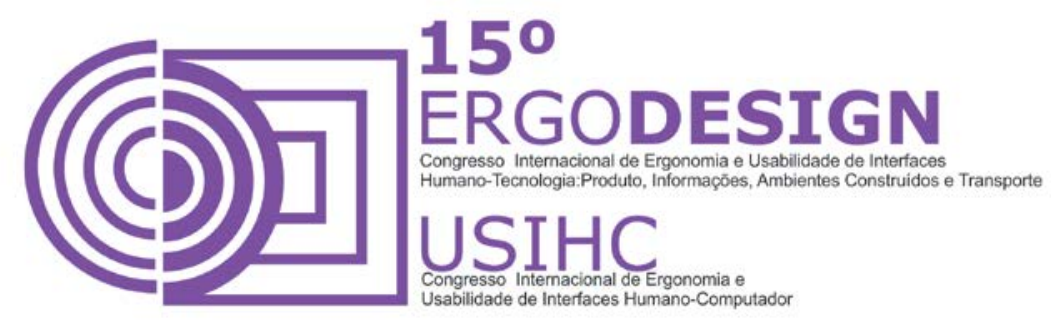

Emergência da Sociedade Brasileira de Cardiologia. Arq. Bras. Cardiologia, São Paulo, v.101, $\mathrm{n}^{\circ}$.2, 2013. Disponível em: <http://www.scielo.br/pdf/abc/v101n2s3/v101n2s3.pdf>. Acesso em: 22 jan. 2014.

INTERNATIONAL ELECTROTECHNICAL COMMISSION. IEC 60878: Graphical symbols for electrical equipment in medical practice. 2ed: IEC, 2003.

INTERNATIONAL ELECTROTECHNICAL COMMISSION. IEC 60601-1-6: Medical electrical equipment. Part 1-6: General requirements for basic safety and essential performance - Collateral standard: Usability. 3ed: IEC, 2010.

MARTEL, Adrian. Application of Ergonomics and consumer feedbck to product design at Whirpool. In: STANTON, Neville. Human Factors In Consumer Products. Boca Raton (flórida): Taylor \& Francis, 1997. p.107-126.

NIELSEN, Jakob. Usability Engineering. Cambridge, MA .Academic Press, 1993

PADOVANI, Stephania; SPINILLO, Carla; GOMES, Ítalo. Desenvolvimento e aplicação de modelo descritivo-normativo para análise de websites. Revista Produção, São Paulo, v.19, n.3, p.514-528, jun. 2009. Disponível em: < http://dx.doi.org/10.1590/S0103-65132009000300009>. Acesso em: 02 nov. 2010.

PREECE, Jennifer. Design de Interação: Além da interação homem-computador. Porto Alegre: Bookman, 2005

SILVA, Barbara Dariano. Avaliação de usabilidade situada para aperfeiçoamento de equipamentos médicos. Dissertação (Mestrado) - Curso de Engenharia Elétrica, Departamento de Engenharia de Computação e Sistemas Digitais, Escola Politécnica da USP, São Paulo, 2008.

URTIGA, Keylla Maria da Silva Torres de Sá. Desenvolvimento de Interface Centrado no Usuário para Sistema Médico Utilizando Conceitos da Interação Humano Computador. Dissertação (Mestrado em Informática em Saúde) - Programa de Pós-graduação de Informática em Saúde, Universidade Federal de São Paulo, 2008.

WODTKE, Christina; AUSTIN, Govella; Information Architecture: Blueprints for the web. Indianapolis: New Riders, 2009. 